\title{
Challenges and strategies among the poor: Focus on urban agriculture in KwaMashu, Durban, South Africa
}

\author{
Hangwelani (Hope) Magidimisha ${ }^{{ }^{*}}$ \\ Human Science Research Council (HSRC) \\ Lovemore Chipungu ${ }^{\mathrm{b}}$ \\ University of KwaZulu-Natal \\ Rosemary Awuorh-Hayangah ${ }^{\mathrm{b}}$ \\ University of KwaZulu-Natal
}

\begin{abstract}
Submitted 20 June 2011 / Revised 2 September, 30 November 2011; 16 February, 16 April, 30 May, 13 July, and 23 July 2012 / Accepted 31 July 2012 / Published online 5 February 2013

Citation: Magidimisha, H. H., Chipungu, L., \& Awuorh-Hayangah, R. (2013). Challenges and strategies among the poor: Focus on urban agriculture in KwaMashu, Durban, South Africa. Journal of Agriculture, Food Systems, and Community Development, 3(2), $109-126$. http://dx.doi.org/10.5304/jafscd.2013.032.002
\end{abstract}

Copyright (C) 2013 by New Leaf Associates, Inc.

\begin{abstract}
Urban agriculture in South Africa historically has been labeled as an illegal activity. The problems caused by this labeling have been compounded by the traditional planning system in South Africa, which does not recognize urban agriculture as a part of the land use in the urban landscape. Despite its illegality, however, current evidence shows that it is commonly practiced by many poor households in developing countries. There is growing evidence that most countries are gradually recognizing the value of urban agriculture to poor households, and to this end they are beginning to realize the

a* Corresponding author: Hangwelani (Hope) Magidimisha, Democracy, Governance and Service Delivery, Human Science Research Council (HSRC); 750 Intutuko Junctions; Durban 4001, South Africa; hangwe2003@yahoo.com

b Architecture, Planning and Housing, University of KwaZuluNatal; King George V Avenue, Shepstone Building; Durban 4041, South Africa
\end{abstract}

importance of incorporating it into their urban policy packages.

Despite this recognition and acceptance of urban agriculture as a livelihood and food-security strategy among the urban poor, little attention is paid to it. This paper explores urban agriculture as one of the survival strategies among the urban poor in Durban's KwaMashu residential area. The focus is on the nature of urban agriculture and the competing challenges associated with it. At the core of some of the challenges are existing legislation and policies that seem to be unresponsive to urban agriculture. Despite this unresponsive legislation, we show that urban agriculture continues to flourish along sensitive areas such as river banks and on road right-of-ways. The paper concludes by arguing that the onus is on the local authorities to promote urban agriculture by putting in place mechanisms that should promote its growth and integrate it into mainstream development plans. 


\section{Keywords}

capital, livelihoods, livelihood approach, urban agriculture

\section{Introduction}

Even though urban agriculture historically has been labeled as an illegal activity, current evidence shows that it is now commonly practiced by many poor households in developing countries (Mbiba, 1995; Mubvami \& Mushamba, 2006). There is growing evidence that most countries are gradually recognizing the value of urban agriculture to poor households; to this end, they are beginning to realize the importance of incorporating it into their urban policy packages. Researchers such as Mbiba (1995) and Rogerson (1997) have demonstrated its economic importance among the urban poor in the cities of developing countries. Despite this recognition and acceptance of urban agriculture as a livelihood and food-security strategy among the urban poor, little attention is paid to challenges that are faced by urban farmers.

Urban agriculture in South Africa falls under the auspices of integrated development planning (IDP). One important aspect that underpins IDPs, and that is also at the core of the current democratic South African government, is the need to ensure that individuals have access to economic opportunities and sufficient nutritious food to satisfy their needs. However, major findings by the Council for Scientific and Industrial Research (Austin\& Visser, 2002) illustrate that:

- In South Africa's urban land use planning, agriculture is not considered an urban land use activity;

- Limited attention is given to utilizing land with high agricultural potential in urban land use planning;

- Urban agriculture is practiced using unauthorized rain-fed water; and

- Urban agriculture often shifts to give way to industrial and residential land use activities.

Although some cities (such as Cape Town and Johannesburg) have already started to integrate urban agriculture as an urban land use, there are still a number of factors that need to be addressed in order for it to be effective. Participants in urban agriculture encounter a wide range of constraints and problems (such as land and resource restrictions) and are unable to address problems on their own. Urban agriculture has contributed to the competition for resources such as land, energy, water, finance, and labor. Using a livelihood approach, this research attempts to further investigate the nature of urban agriculture practiced in low-income residential areas of cities in South Africa. The focus is on KwaMashu, a low-income neighborhood in Durban.

\section{Methodology}

The aim of the current research was to identify survival strategies and challenges among the urban poor who practice urban agriculture. This paper is based on data collected in Section G of KwaMashu in Durban. The research is informed by both secondary and primary data sources. Secondary sources provided both theoretical and current information on the subject. Primary data was collected by using three key tools: mapping, questionnaire surveys, and observations. Household surveys were given to a sample of 30 households randomly selected from a sampling frame of 83 practicing urban farmers. In addition, interviews were carried out with key informants, including senior officials from the municipality and community leaders, some of whom were identified through the snowball approach. Observation together with mapping afforded an opportunity to see and record activities both on the maps and photographically. Despite minor setbacks such as those involving the absence of household heads and the reluctance of some households to participate in the survey, it is the researchers' belief that the data collected and used for this paper is adequate to provide a generalized view of urban agriculture in KwaMashu. As can be seen from maps 1 and 2, the area chosen in KwaMashu, Section $G$, represents the central and most active area in the practice of urban agriculture. 


\section{Map 1. Land Use Zones in KwaMashu, Durban, South Africa}

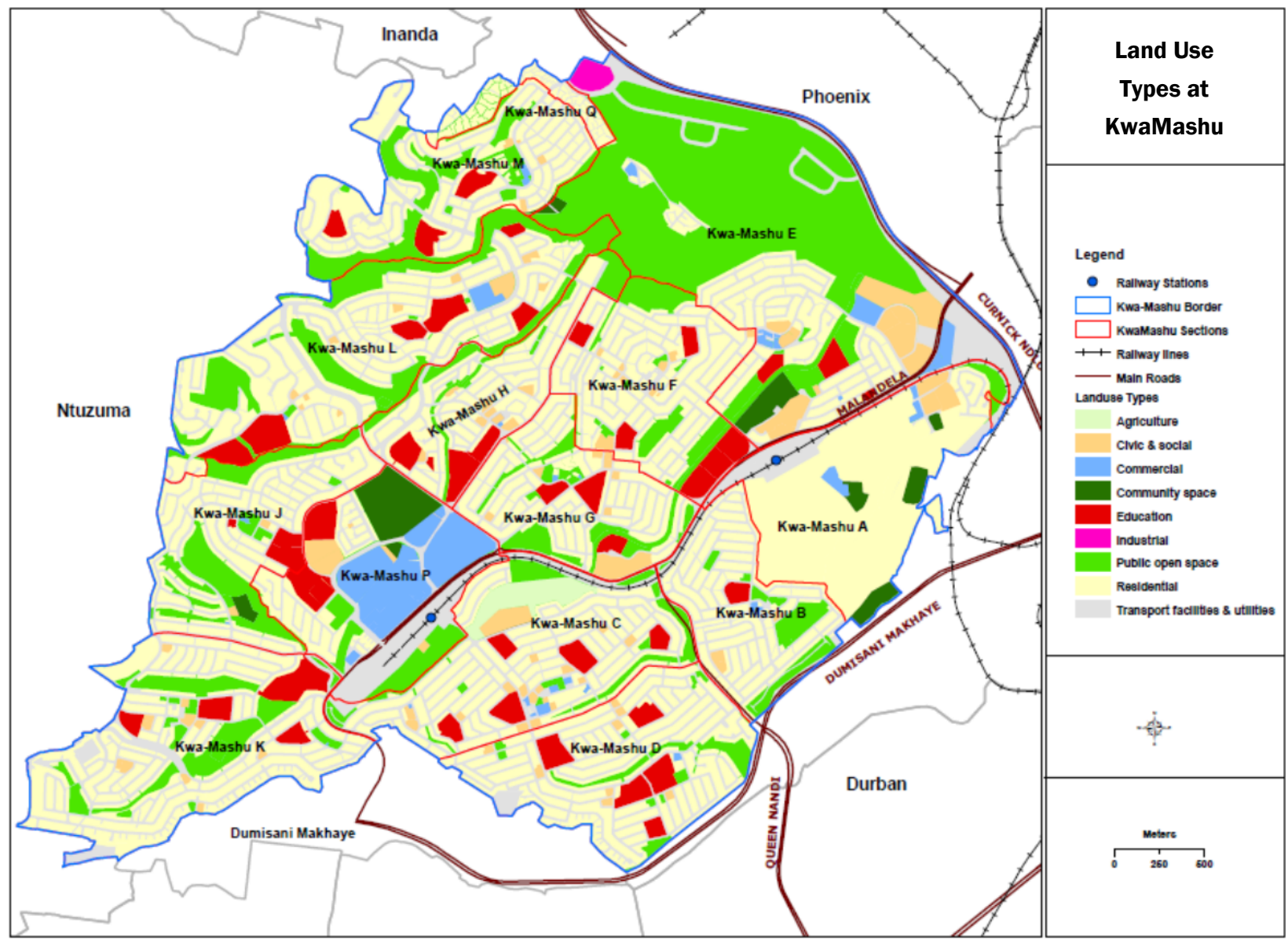

Source: Prepared by H. H. Magidimisha, 2009.

However, the study has methodological and practical limitations, due especially to the small number of interviewees, which in essence defined the scope of the study. While the small number of interviewees enabled the researchers to identify key issues, respondents cannot be considered to be representative of the wider city. Therefore, followup research should involve much larger numbers of households and even include some outside KwaMashu but within Durban. The practical limitations were mainly a result of the budgetary constraints that dictated the sample size and the short duration spent conducting fieldwork. However, the reliability of the study must be understood in the context of other research on a similar topic, whose responses are more or less similar to those provided in this research.

\section{Framework for Analysis}

\section{The Livelihood Approach}

This approach is based on the premise that the survival of the urban poor depends on a multiplicity of activities that are used as sources of livelihood. Chambers and Conway (1992) note that "A livelihood comprises the capabilities, assets (including both material and social resources), and activities required for a means of living" (p. 22). Chambers and Conway (1992) further argue that as a tool, the livelihood framework provides the basis for a shared point of reference in order to analyze and identify appropriate intervention measures for livelihoods.

The approach is grounded in the understanding of households' access to a portfolio of assets, both tangible and intangible, and accessibility to 
Map 2. Land Used for Urban Agriculture in KwaMashu, Section G

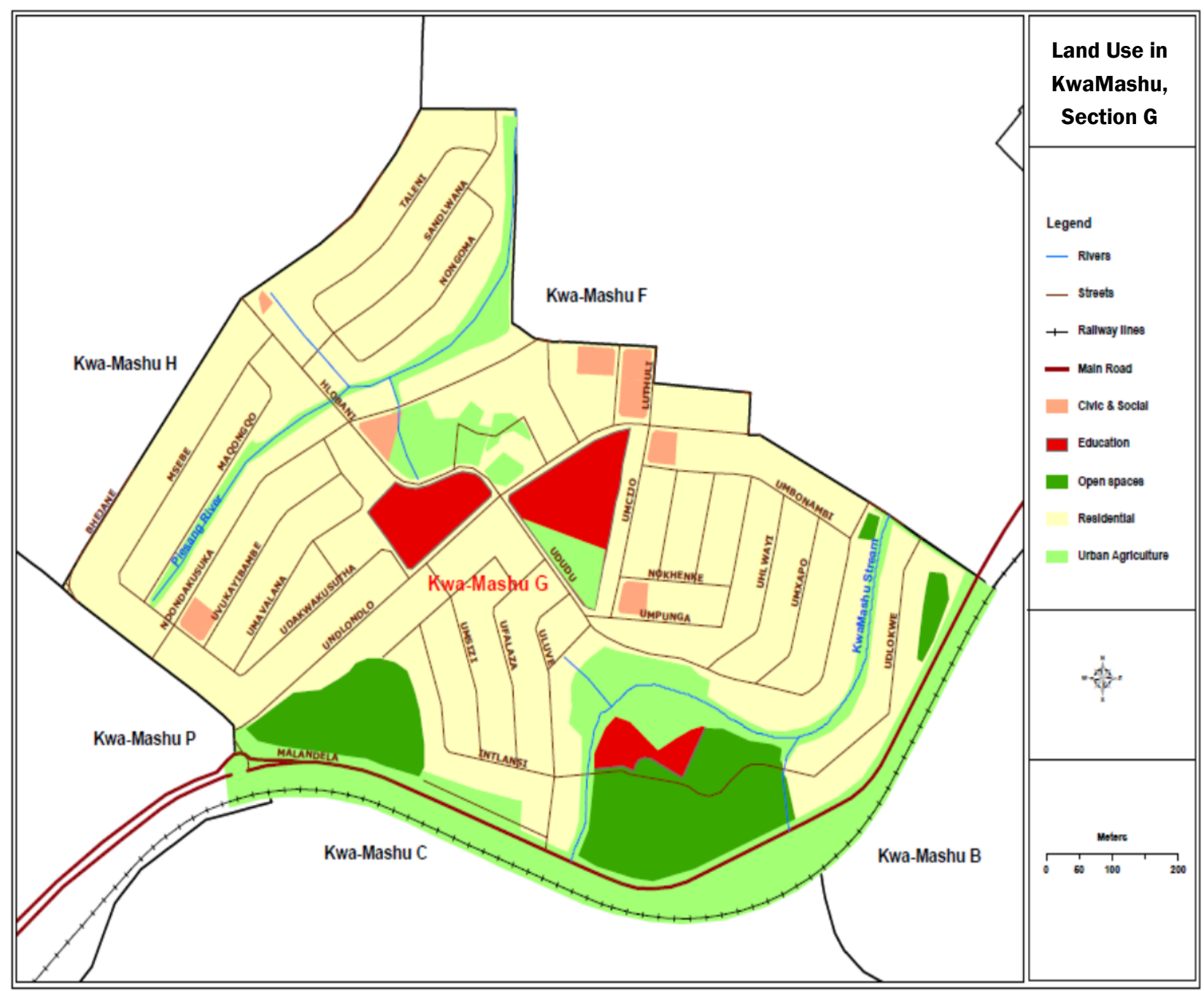

Source: Prepared by H. H. Magidimisha, 2009.

rights that they capitalize on to change their lives. Among such assets are finance, human, natural, physical and social (Coovadia, 1995; Kekana, 2006; Rakodi \& Lloyd-Jones, 2002).

Financial capital can be described as income obtained from the sale of labor, pensions, and remittances. When income is in surplus, households can change it into financial capital by saving or transforming it into tangible assets. Such capital is essential for households since they can use it to cushion themselves against stresses and shocks. Financial capital can also be obtained through access to credit, which households can use to develop enterprises or invest into some sort of infrastructure.

Another asset identified above is human capital, which comes in the form of labor, health, education, and related skills (Chambers \& Conway, 1992). Labor is simply defined as the ability to work and is fundamentally dependent on the health of household members. In addition, the value of human and financial capital is improved through education as well as other related skills obtained through training in various fields.

Equally important is natural capital, which comes in the form of natural resources such as land, forests, and natural water resources. Ayaga and colleagues (2005) note that although natural 
capital is not a significant asset for the urban poor, it can be used for urban agriculture. Unfortunately, urban agriculture is most often practiced by the urban poor on marginal land such as contaminated land (Ayaga, Kibata, Lee-Smith, Njenga, \& Rege, 2005). Other forms of natural capital are also seen as less significant in urban areas. Rivers, for instance, are viewed as major sources of water for domestic and industrial use in the urban economy. Forests, on the other hand, are viewed as indirect contributors to the quality of the human environment by enhancing the aesthetic value of built environments.

Physical capital as an asset comes in the form of housing, livestock, and economic and social infrastructure. Rakodi and Lloyd-Jones (2002) note that housing is the most important asset for the urban poor since its use is diverse. They point out that housing can be rented out, or part of the house can be used as a tuck shop (a small food retail shop), and the space around the house can be used for market gardening. Similarly, livestock in urban areas is generally reared as a food supplement, but at times is sold. Physical capital also comes in the form of public infrastructure, including municipal engineering services such as roads and sewer and water networks. Social infrastructure, on the other hand, comes in the form of schools and health facilities (Krantz, 2001). Access to such services provides households with an opportunity to improve their human capital. Above all, access to equipment in the form of machinery and tools is vital for enhancing household enterprises.

The last type of asset is in the form of social and political capital. This manifests itself in the form of social support mechanisms and information. Carney (2005) elaborates on this by noting that this asset includes social resources (such as networks, trust, and reciprocity) in the way people interact and pursue their livelihoods. This network of support and reciprocity in communities provides poor households with access to loans, child care, food, and shelter. The success of such networks is dependent on access to information about opportunities and problems such as availability of casual labor markets. Krantz (2001) notes, however, that social networks supportive of the poor are generally thought to be less robust in urban areas because of the mobility and heterogeneity of the population.

\section{Sustainable Livelihood Approach}

A very important development in the literature on livelihoods was the transformation of the traditional livelihood approach through the inclusion of sustainability. This led to the birth of sustainable livelihoods, a concept first introduced by the Brundtland Commission on Environment and Development as a way of linking socioeconomic and ecological considerations in a cohesive, policyrelevant structure. The 1992 United Nations Conference on Environment and Development (UNCED) expanded the concept, especially in the context of Local Agenda 21 (an action agenda for multilateral organizations and individual governments in dealing with sustainable development), and advocated for the achievement of sustainable livelihoods as a broad goal for poverty eradication (Krantz, 2001). It stated that sustainable livelihoods could serve as an integrating factor that allows policies to address development, sustainable resource management, and poverty reduction simultaneously. The traditional definition of sustainable livelihoods as provided by Chambers and Conway (1992) recognizes that:
A livelihood comprises the capabilities, assets (stores, resources, claims and access) and activities required for a means of living: a livelihood is sustainable which can cope with and recover from stress and shocks, maintain or enhance its capabilities and assets and provide sustainable liveli- hood opportunities for the next genera- tion; and which contributes net benefits to other livelihoods at the local and global levels and in the long and short term. (pp. 7-8)

As can be noted from the definition, key departures from the traditional approach to livelihoods are the inclusion of environmental and social sustainability, which addresses external impacts on local and global resources as well as the internal capacity of livelihoods to withstand outside 
pressure (such as shocks and stresses). Depending on their nature, these external pressures can be continuous, cumulative, predictable, and at times traumatic. Such experiences have led to the argument by some researchers (such as Chambers and Conway, 1992) to include the ability to avoid, or more often to withstand and recover from, such stresses and shocks in the definition of sustainable livelihoods.

Therefore, the sustainable livelihood approach to development provides an understanding of the issues affecting livelihoods in a household, community, region, or country. Key elements of this approach include people's assets, vulnerabilities, opportunities, outcomes, and livelihood strategies as well as the institutional framework (Chambers \& Conway, 1992; Rakodi \& Lloyd-Jones, 2002).

However, the most important aspect of the sustainable livelihood approach is that it goes beyond the traditional livelihood approach in terms of recognizing and understanding areas of concern where there is a need for intervention. It identifies the complexities of various factors and how they impinge on development. The approach recognizes the importance of human capabilities, types of capital, vulnerabilities, opportunities, and strategies as well as policies, institutions, processes, and organizations. In this regard, it is a useful framework for structuring and analyzing the situation and how policies and services are affecting it. This is done using a holistic overview of how different elements in development are addressed. Above all, it is an important tool that can be used to evaluate impacts that result from certain developmental interventions.

The value of the sustainable livelihood approach in this research is further elaborated by how normative and operational principles operate in practice. These principles are yardsticks of best practice shared widely by development practitioners. A number of authorities (such as Carney, 2005; Krantz, 2001; and South Africa Department of Environmental Affairs and Tourism, 2000) noted that normative principles of the sustainable livelihood approach are people-centered, empowering, holistic, and sustainable, as well as responsive and participatory.
Despite having such positive implications, the sustainable livelihood framework has been criticized for being too broad - a factor that could create implementation challenges. Since it is a tool designed for rural development, critics have further questioned its applicability in the urban environment, where natural resources and seasonality are less salient (Parkinson \& Ramírez, 2006). Hence discretion is required when applying it in the urban context. An equally important critique is overemphasis on the notion of self-help with a focus on the complexity of poor households' livelihoods, which seems to underemphasize macroeconomic and political issues (O'Laughlin, 2004; Toner, 2002). However, although the livelihood approach has these weaknesses, it still remains a useful analytical tool for development at microeconomic levels.

\section{The Case of KwaMashu, Durban}

\section{Background}

KwaMashu is located in the north of the eThekwini municipal area, close to the new zone of economic growth. It is approximately 11 miles (17 $\mathrm{km})$ to the northeast of the city center of Durban. KwaMashu is a high-density residential area with approximately five to seven inhabitants per household. It covers 5.8 square miles (15 square $\mathrm{km}$ ) and is made up of approximately 12 neighborhoods. As an Apartheid development, built between 1957 and 1970, KwaMashu was born out of the need to mop up what the Apartheid regime believed to be the "mess" that was gradually accumulating in Cato Manor in Durban Central. The crisis of Cato Manor largely emanated from the segregatory policies of the Apartheid regime that excluded nonwhite racial groups (especially blacks) from residing in the urban centers. The accumulation of Africans and Indians in Cato Manor resulted in the forced removal of these residents of Cato Manor to areas outside the city, such as KwaMashu, Phoenix, and Umlazi. Hence when it was developed, its administration was outside and separate from the general administration of the city of Durban. However, the first democratic election in South Africa in 1994 saw the ushering in of a new era. KwaMashu was politically reintegrated 
into Durban Municipality. It is among the 46 racially separated local government entities that were integrated into Greater Durban through the six local councils that constituted the Transitional Local Councils, later becoming part of Durban Metropolitan Council (Onyago, 2010). This change meant that KwaMashu was supposed to benefit from the new administration through better infrastructure, among other services. This integration went further in the year 2000 when the government consolidated large rural areas into one council under the new name of eThekwini Municipality.

\section{Socioeconomic Profile of KwaMashu}

Statistical data (Statistics South Africa, 2007) shows that KwaMashu has a total population of 38,169 and the majority of these (99.9 percent) are black Africans. There are more females (52 percent) than males in the area, a factor that explains why most households in the area are female-headed. The dominate age group in KwaMashu is between five and 34 years of age, which represents approximately 41 percent of the total population. The dependent age group (of between zero and 4 years) and the old-age group (65 years and above) contribute only 10 percent and 3 percent, respectively, to the population of KwaMashu (Community Survey, 2007).
The demographic profile of KwaMashu further shows that there is a high proportion of people who are dependent to those who are independent. This is observable by looking at the number of people who are employed, unemployed, and not economically active. The statistics on employment status shows that 35 percent of the population is not economically active and 36 percent are not employed, as compared to only 29 percent who are employed. About 50 percent of the population in KwaMashu earn below the 2006 food poverty line of R2,508 per annum (Republic of South Africa, 2006, p. 8). This is inevitable given that up to 28 percent of KwaMashu residents do not earn any income at all (table 1).

The development of KwaMashu was meant to provide a self-contained residential area for black Africans on the periphery of the city of Durban. The provision of public facilities was seen as one of the major ways of achieving this aim. There are a number of public facilities that are available in KwaMashu, including schools (13), health centers (4), commercial centers (2), libraries, and open spaces, among others.

The Characteristics of Urban Farmers in KwaMashu Gender, employment status, educational level, and house ownership give insights into the identity of

Table 1. Household Income Levels in KwaMashu

\begin{tabular}{lcc}
\hline Household income (per annum) & Household & Percentages \\
\hline No Income & 2,422 & 28 \\
\hline R1-R4,800 (USD0.15-USD717.07) & 506 & 6 \\
\hline R4,801-R9,600 (USD717.22-USD1,434.14) & 1,541 & 17 \\
\hline R9,601-R19,200 (USD1,434.29-USD2,868.29) & 1,626 & 18 \\
\hline R19,201-R38,400 (USD2,868.44-USD5,736.57) & 1,420 & 16 \\
\hline R38,401-R76,800 (USD5,736.72-USD11,473.10) & 831 & 9 \\
\hline R76,801-R153,600 (USD11,473.30-USD22,946.30) & 315 & 1 \\
\hline R153,601-R307,200 (USD22,946.40-USD45,892.60) & 93 & 0 \\
\hline R307,201-R614,400 (USD45,892.7-USD91,785.20) & 18 & 0 \\
\hline R614,401-R1,228,800 (USD91,785.30-USD183,570) & 3 & 100 \\
\hline Total & $\mathbf{8 , 7 7 5}$ & 1 \\
\hline
\end{tabular}

Source: Statistics South Africa, 2007. 
Figure 1. Gender Distribution in the Practice of Urban Agriculture $(\mathrm{N}=30)$

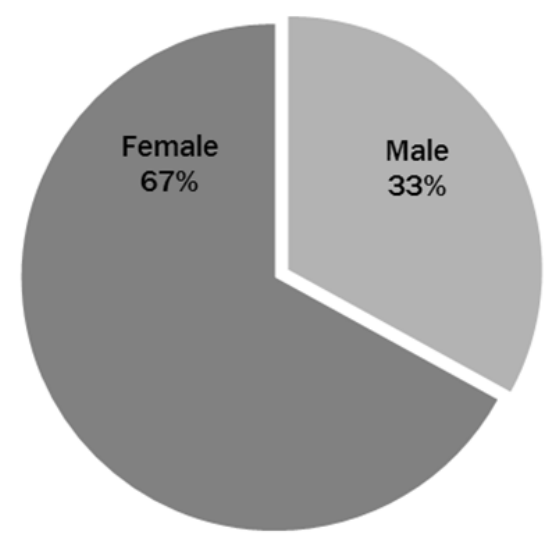

urban farmers. Data from the survey shows that urban agriculture in KwaMashu is largely practiced by female members of the community (67 percent) (see figure 1). From a purely traditional perspective, such a scenario is expected since it is believed that men spend most of their time away from home (possibly at work) while most females are left at home attending to household chores. The situation is further enforced by the nature of the employment sector, where there are more job opportunities for men.

The educational status of urban farmers also varies considerably. The majority of urban farmers

Figure 2. Educational Levels of Urban Farmers $(N=30)$

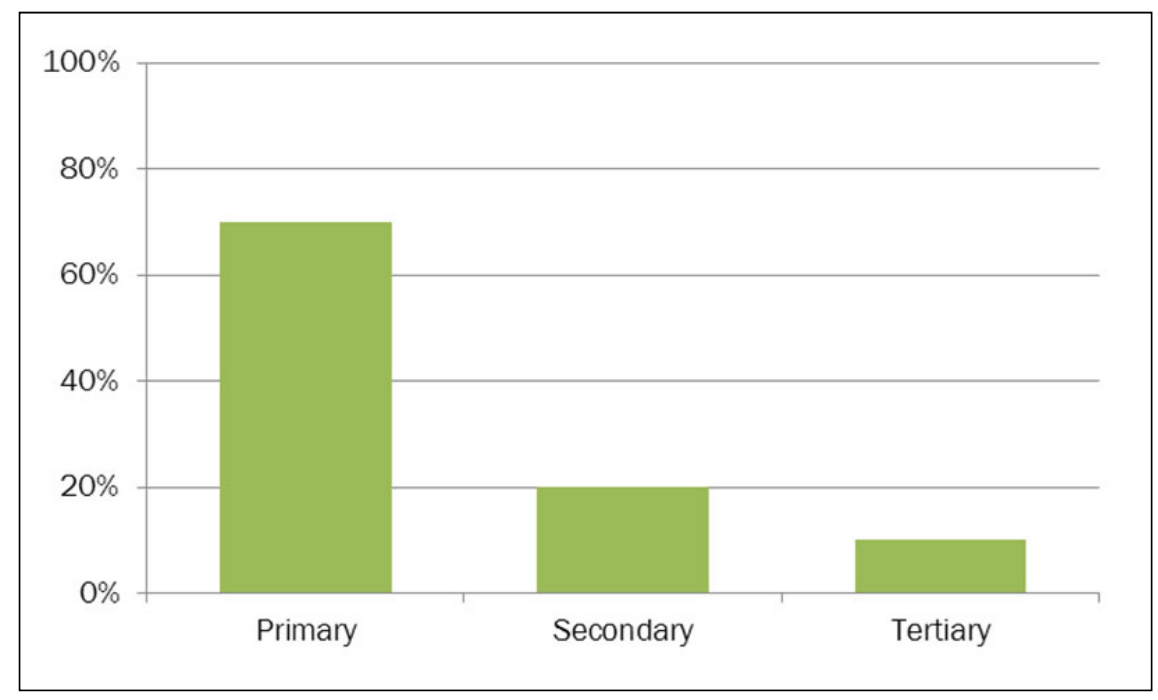

Figure 3. Employment Status of Urban Farmers $(\mathrm{N}=30)$

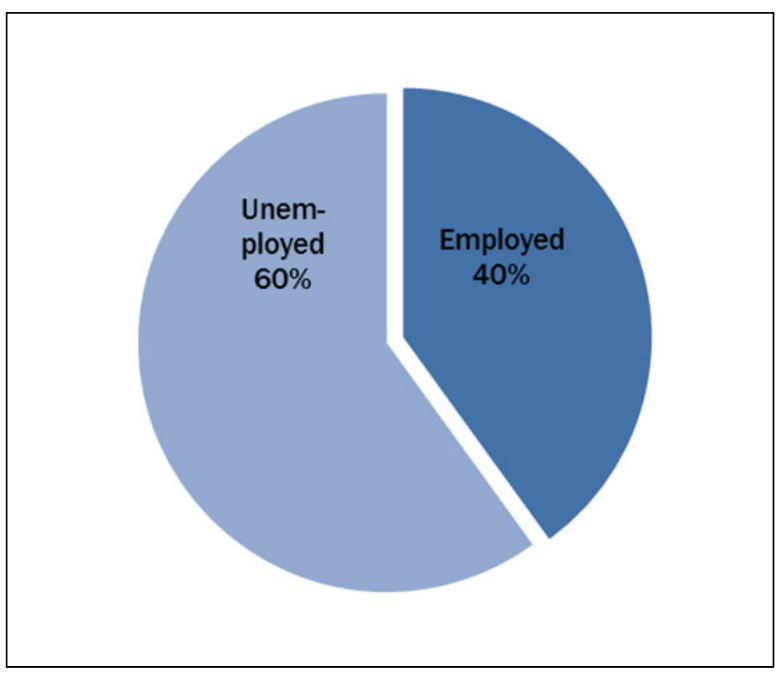

(67 percent) have primary education, with only 13 percent having achieved tertiary education (see figure 2). This low level of education sheds light, to some extent, on why most urban farmers (60 percent) are unemployed or employed in lowincome jobs (figure 3). Such poor educational levels combined with poor employment opportunites negatively affect the incomes of these households. As indicated in table 2, 60 percent of the urban farmers are in the low-income bracket where they earn less than R5,000 (approximately USD640) per month.

For these low-income residents to survive, they need to find ways of supplementing their food and incomes; urban agriculture is one means they use to sustain their lives. But it has to be remembered that KwaMashu is a low-income residential area, and as such most households have low incomes and some rely on the Department of Social Welfare for support. This observation is in line with other researchers' observations (such as Reddy and Sokomani, 2008, and Vorster, 2006) that social supports play an 
Journal of Agriculture, Food Systems, and Community Development

ISSN: 2152-0801 online

www.AgDevJournal.com

Table 2. Household Income of Urban Farmer Respondents in KwaMashu ( $n=15$ )

\begin{tabular}{llcc}
\hline Categories & Household income (in Rands / USD) & Number & Percentage \\
\hline Marginalized & None & 3 & 20 \\
\hline Urban poor/Low income & $2,501-5,000$ / 321.32-642.39 & 9 & 60 \\
\hline Middle income & $5,001-10,000 / 642.52-1,284.77$ & 2 & 13 \\
\hline High income & 10,001 or more / 1,284.90 or more & 1 & 7 \\
\hline Total & & 15 & 100 \\
\hline
\end{tabular}

Note: As of June 1, 2009 (the approximate date of this survey), 1 Rand = USD7.78

important role in improving household food and security for most South African households. It can therefore be concluded that vulnerable households engage in urban agriculture.

Another important aspect of households practicing urban agriculture in KwaMashu is their tenure status. The survey results generally showed that urban agriculture is practiced by both landlords and tenants: 53 percent of respondents are not homeowners, while 27 percent are homeowners (see figure 4). The other subsection, representing 20 percent of the respondents, has no proper tenure status: either they are staying in their parents' houses or they are custodians of houses left behind by friends and relatives who are away.

When comparing the tenure status of these housesholds to the practice of urban agriculture, only 10 percent of homeowners engage in urban agriculture. On the other hand, only 4 percent of households in the rental category do not practice urban agriculture. We can safely argue that urban agriculture is a survival strategy for the urban poor, especially nonproprty owners. In the context of low-income residential areas, these nonproperty owners may be renting one or two rooms, which they can afford when compared to renting the whole house. For them to survive, they engage in other survival strategies, such as urban agriculture, in order to cushion themselves from various economic problems.

In summary, it can be concluded that urban agriculture is practiced by the vulnerable members of society. This level of vulnerability is exhibited by the type of people who mostly practice urban agriculture (i.e., women), their low academic status, low incomes, and unsustainable tenure status.
Figure 4. Tenure Status of Urban Farmers $(\mathrm{N}=30)$

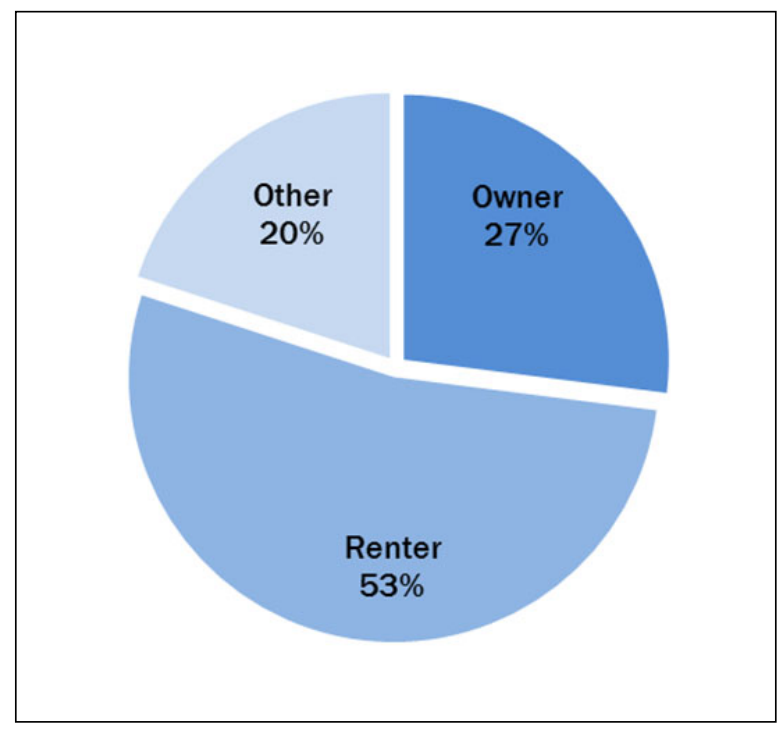

From this perspective, we conclude that urban agriculture is used as a shield against adverse economic problems by vulnerable households in lowincome areas.

The Nature of Land for Urban Agriculture in KwaMashu Like the practice of any other type of agriculture, urban agriculture in KwaMashu can be described along a number of dimensions. Among these are places where urban agriculture is practiced, types of commodities produced, and what those commodities are used for, as well as challenges faced by these urban farmers.

Research results from KwaMashu show that urban agriculture is practiced on land not specifically designated for this purpose. Instead, it is practiced either onsite (i.e., on residential plots 
such as backyards) or off-site (i.e., on undesignated open spaces, roadsides, railway reserves, and river valleys), as shown in figure 5 . The only land that is easily accessible and legally permitted for urban agriculture is onsite, but the site selected also depends on the type of urban agriculture being practiced.

In both instances (onsite or off-site), the sizes of the plots are small. This has negative implications for the diversity of agricultural practice. Significantly affected by land constraints are livestock (especially goat) farmers, who do not have enough space for grazing their animals, and certainly not for growing animal feed. Instead farmers depend heavily on buying animal feed - a factor that further negatively affects their finances. In addition, because of land constraints, these farmers cannot breed goats on their plots; instead, they must buy them from farmers in the Eastern Cape (see plate 1). This has significantly affected their scales of operation while at the same time pushing up their production costs.

Despite the fact that onsite plots are small, it appears that they are popular among farmers due to the proximity to their homes. Such proximity ensures security of their products. In addition, the availability of infrastructure such as water and electricity allows for some kind of diversity, albeit on a small scale. It is common to find both crop production and poultryraising being practiced on
Figure 5. Distribution of Urban Agriculture Sites in KwaMashu $(\mathrm{N}=30)$

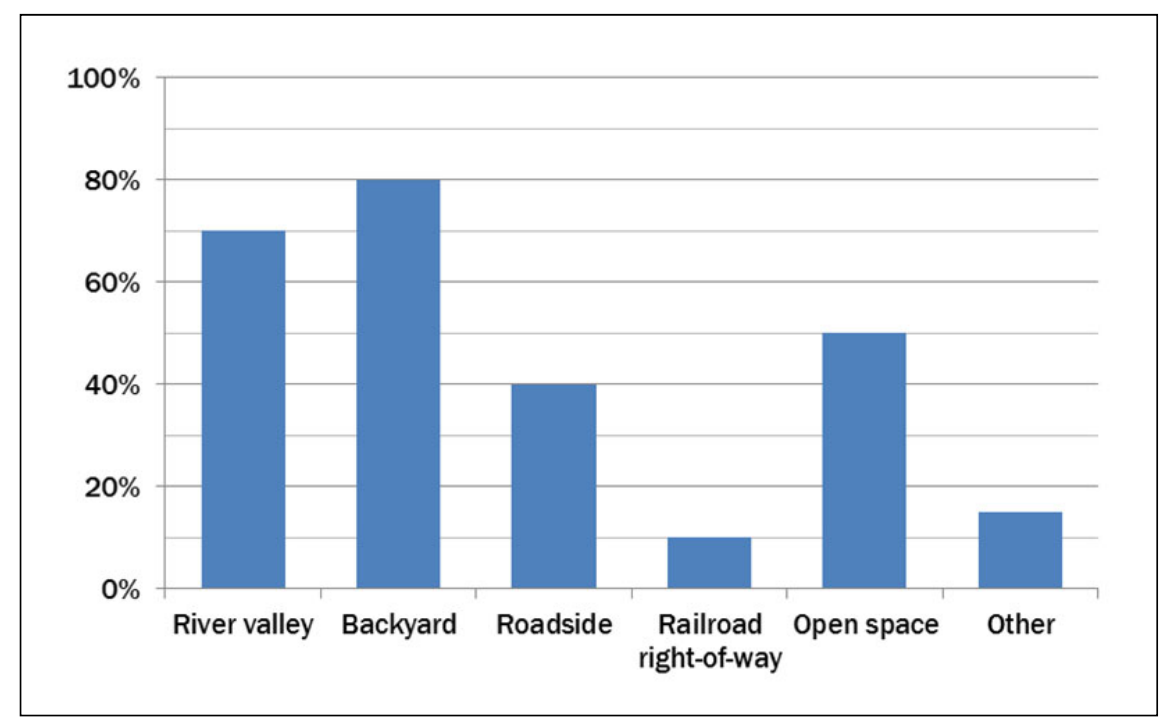

onsite plots. But it has to be pointed out that onsite urban agriculture is mainly practiced by the small percentage of urban farmers (27 percent) who own houses. The fact that onsite cultivation involves use of water and electricity means that those who rent rooms from homeowners do not have the right to practice this because it increases the cost of
Plate 1. Livestocking in KwaMashu: Goats Purchased Transported from the Eastern Cape Are Transported to KwaMashu

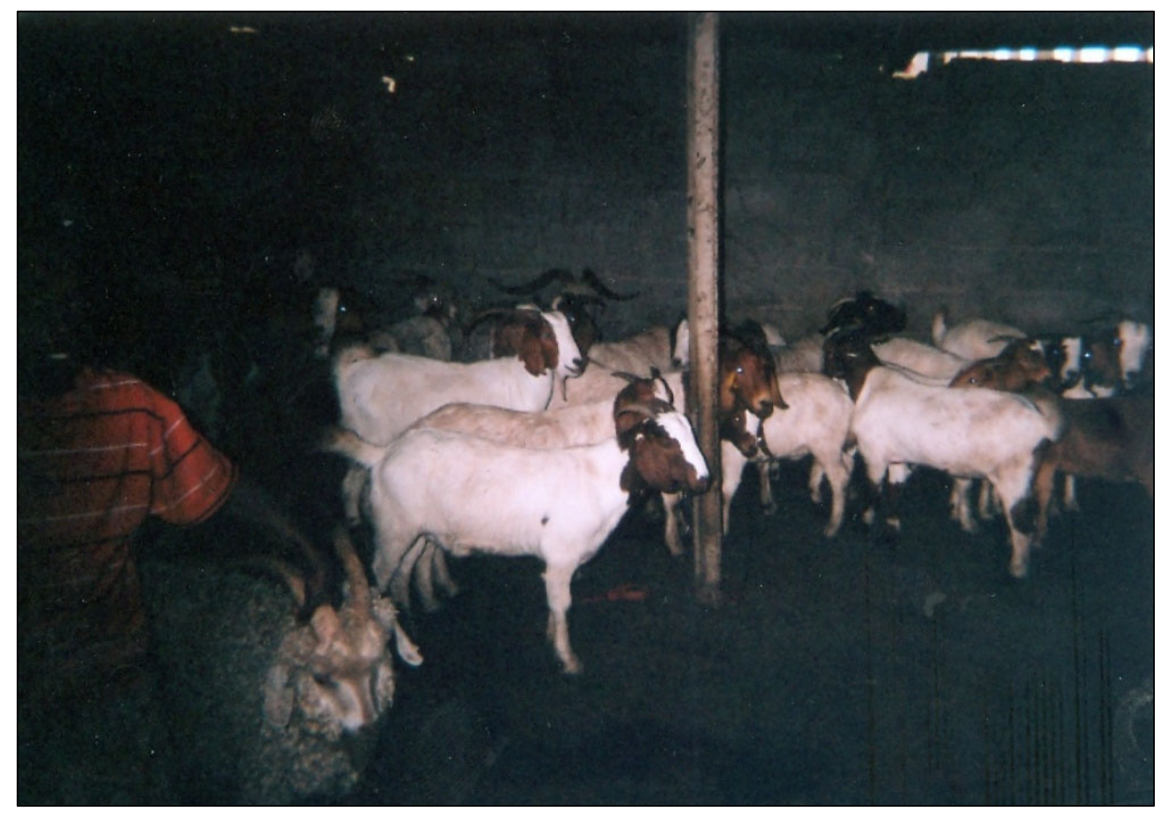

Photo by H. H. Magidimisha, 2009. 


\section{Plate 2. Types of Vegetables Grown in an Off-site Plot in KwaMashu}

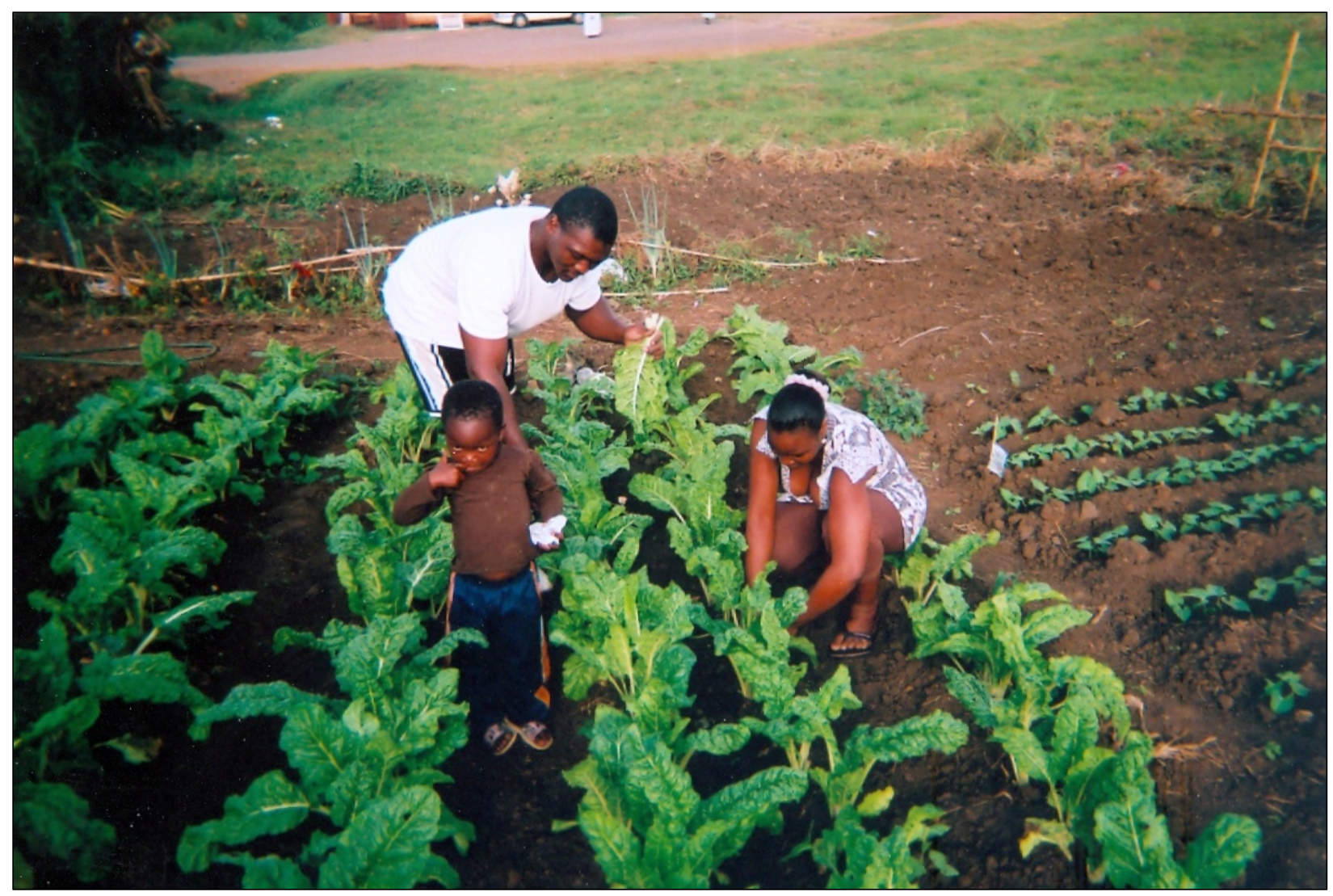

Photo by H. H. Magidimisha, 2009.

infrastructure.

While it can be agued that plots for urban agriculture are small in general, their sizes depend on location. For instance, most plots on roadside curbs and railway reserves are smaller compared to those on land designated as open spaces. Urban agriculture on the former plots is seasonal (with the exception of livestock-raising) since it is highly dependent on seasonal rainfalls. In some instances, people opt to use riverbanks where they can irrigate their crops using water from polluted rivers. On these plots, a variety of crops are grown and agriculture is a year-round activity. Crops grown on off-site plots include a variety of vegetables such as tomatoes, spinach, beans and onions, as shown in plate 2. Unfortunately, urban agriculture on most offsite plots is a risky activity since most products are stolen before reaching proper maturity. This explains why only 40 percent of the urban farmers interviewed raise livestock (as opposed to 70 percent who are engaged in growing vegetables), since it is expensive to put security measures in place to safeguard livestock.

The products from urban agriculture are put to a variety of uses, the most common being for domestic consumption (approximately 80 percent). Some urban farmers sell their products, but this is a very small proportion, just 15 percent. Some farmers grow their products for charity, donating them to preschools, domestic workers, and destitute people, as well as to neighbors. However, some farmers never enjoy their products since they are stolen before they are harvested. Figure 6 summarizes the uses of urban agricultural products.

\section{Summary of Fieldwork Results}

From the foregoing information, it has been noted that the unavailability of land designated for urban 
agriculture has resulted in people farming any accessible piece of land. This in turn may conflict with other land uses, especially where planned land uses have been informally replaced by urban agriculture. Cultivation in most low-lying areas may impede urban infrastructure such as water and sewer lines. For instance, a number of crops were observed blocking access to sewer manholes, while others (such as maize) on road verges obscure visibility on roadsides. In addition, the lack of recognition for urban agriculture as a land use has negatively affected farmers' ability to expand their production; similarly, they could not use the land as collateral to obtain capital from banks. Hence the lack of recognition has deprived urban farmers of opportunities to expand and diversify their activities.

\section{Emerging Issues}

A number of issues emerge from the analysis of urban agriculture in KwaMashu. These come in the form of challenges the urban farmers are facing, among which are lack of land, high production risk, lack of water and electricity, lack of finance, lack of representation, and inadequate technologies; these are detailed in table 3. We now discuss these challenges in the context of the portfolio of assets identified in the framework for analysis: financial, human, natural, physical and social capitals.

\section{Natural Assets and Urban Agriculture}

The importance of natural capital (such as land and rivers) for the survival of the urban poor was

Table 3. Challenges to Urban Agriculture According to Survey Respondents $(\mathrm{N}=30)$

\begin{tabular}{lccc}
\hline Challenges & $\begin{array}{c}\text { Respondents } \\
\text { (Number) }\end{array}$ & $\begin{array}{c}\text { Respondents } \\
\text { (\%) }\end{array}$ & Rank \\
\hline Lack of land & 26 & 87 & 1 \\
\hline High production risks & 26 & 87 & 1 \\
\hline Lack of finance & 23 & 76 & 3 \\
\hline Lack of water, electricity & 20 & 67 & 4 \\
\hline Lack of representation & 16 & 53 & 5 \\
\hline Inadequate technologies & 15 & 50 & 6 \\
\hline
\end{tabular}

Figure 6. Uses of Urban Agriculture Products $(\mathrm{N}=30)$

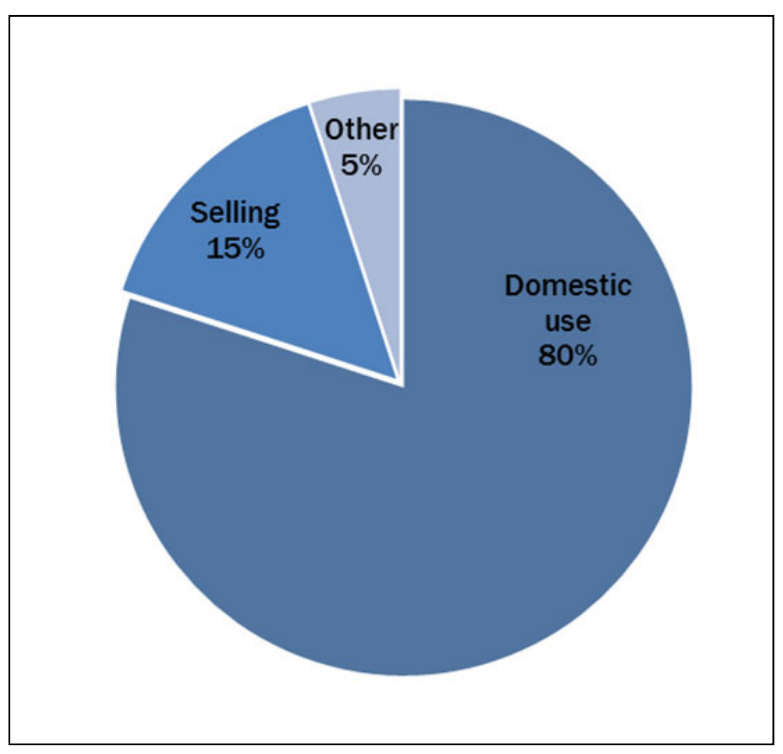

underlined by Ayaga et al. (2005), who noted its significance in urban agriculture. This significance is further raised by the respondents who observed that natural capital, especially land, was one of the major challenges that affected their productivity in urban agriculture. As can be observed in table 3, lack of land is ranked as one of the top challenges that urban farmers face in KwaMashu. The 26 respondents argued that it was mainly the inavailability and unsuitability of land that was a cause of concern. On the part of urban nonfarmers, the unavailability and unsuitability of land are the main reasons that they do not engage in urban agriculture. This, they further argue, is aggravated by a number of risks already outlined in the preceeding paragraphs. This to some extent explains why poverty among urban residents is high, since most of them do not have access to natural capital such as land to engage in agriculture. Derek Davids (2006), for instance noted that only 48.5 percent of households in low-income residential areas of South Africa are able to get enough food for their needs. The same sentiments are shared by Altman, Hart, and Jacobs (2009), who note that the majority of 
people who are in poverty are rescued by the government's social grants.

For urban farmers, crafting a livelihood out of inadequate and unsuitable land is further complicated by risks associated with practicing urban agriculture. These risks are highest on off-site plots (such as roadsides and railways reserves) and are associated with lack of rights and security. When urban agriculture is practiced on these types of land, it is difficult for farmers to exert any form of security of tenure or right to use such land. Hence they cannot put any security measures such as fences in place to protect their crops. During an informal interview with some urban farmers, one remarked that there was no reason to create terraces or improve the soil if there are no guarantees that they will reap their benefits from the land in the long run.

Urban farmers cannot approach financial institutions for capital to invest into agriculture since they cannot offer land they do not own as collateral. These views are shared by some officials from the municipality, who noted that there is no clear legal framework that allows urban agriculture in such places and so there is no guarantee that their activities can be safeguarded. This is true despite the fact that the municipality does not destroy crops on illegal plots and it even leaves the crops intact when maintaining roadsides and railway right-of-ways. The issue of insecurity is compounded by the fear of possible action the local authorities can take in the event of farmers investing in land. It is generally known, for instance, that there are a number of regulations that govern land use on riverbanks, such as environmental laws that include the National Environmental Management Act of 2003 (National Environmental Management Act No. 46, 2003). But given the lax development controls in place, households practice urban agriculture in environmentally sensitive areas and no action is taken by the authorities.

It appears that the issue of land is critical in the municipality as a whole, especially given the rugged nature of Durban. The official position on land for urban agriculture is that land is critical not only for urban agriculture, but also for other uses such as housing. One official further remarked that:
I do not see why the municipality should put land aside for urban agriculture while people do not have housing, people do not sleep in the gardens, and they need shelter.

This statement indicates the failure to understand the value of housing among the poor, which goes beyond the physical construction of the house and includes activities that contribute to the livelihoods of households, such as urban agriculture. But this is not surprising because it is the same experience urban farmers go through in other cities where some authorities even argue that urban agriculture damages the environment (Njokwe \& Mudhara, 2008; Onyango, 2010).

\section{Physical Capital and Urban Agriculture}

Urban agriculture, like any other urban activity, requires the support of physical capital such as housing and physical infrastructure. The importance of such infrastructure was underscored by Rakodi and Lloyd-Jones (2002) and McCallum and Benjamin (1985), who noted that housing as a package of services provides more than shelter, including some economic benefits. The survey results in KwaMashu further illustrate the value of physical capital, especially houses. Homeowners capitalize on them to diversify their sources of livelihoods. As indicated by the survey results, of the homeowners, 90 percent do not engage in urban agriculture. This indicates that they have other means of obtaining income to sustain themselves, such as renting out rooms. For the 10 percent of homeowners who do engage in urban agriculture, they also receive income from renting. In addition, these homeowners have viable agriculture on other plots, though on a small scale, since their onsite plots give them security and access to physical infrastructure such as water and electricity. These benefits are not enjoyed by other urban farmers who do not own houses.

On the other hand, urban infrastructure, as observed by Robinson, Brown, Todes, and Kitchin (2003), provides services that support economic growth by increasing the productivity of labor and capital. To this end, if urban agiculture is to be viable there must be adequate infrastuctural support. This is one of the major problems experi- 
enced by urban farmers who farm on off-site plots, who do not have access to water, electricity, and roads to support their farming activities. This view was echoed by 67 percent of survey respondents, who confirmed that lack of infrastructure was a drawback to agricultural development in the urban areas since it restricts the practice. For example, they are restricted to seasonal, rain-fed agriculture because where plots are accessible there is no water available to allow irrigation for year-round production. Where water is available on residential plots, the sizes of the plots are not large enough to support financially sustainable agricultural activities. Similarly, the lack of electricity reduces diversity in agricultural practice. Electricity could be a major factor in enhancing security for off-site plots.

\section{Social Capital and Urban Agriculture}

Social capital, which is highly dependent on reciprocity and trust, is a major factor that can contribute to the success of livelihood activities on both small and large scales. The success of livelihood activities in rural areas to some extent is a result of networks that households put together to assist each other in various ways, such as in providing labor and protecting homes and crops from marauding wild animals. However, in the context of KwaMashu, the response rate of 87 percent indicating that urban agriculture is a risky business (table 3) is an indicator of weak if not nonexist social networks. One of the respondents remarked that,

Every time I plant my crops by the roadside, people steal them. I feel very discouraged to continue planting since I am not sure whether I will be able to reap what I sowed.

This clearly shows the level of helplessness among individual households. In fact, it indicates that urban agriculture as an activity is highly individualistic and practiced only by those households that are vulnerable. The inability of households to protect their products from theives in both community and individual plots is not only a pointer to the high crime rates experienced in such areas, but further points to the inadequacy of commodities such as food among low-income people. One would indeed surmise that the motive for stealing in most cases is a desperate need for food. This risk relates to lack of security that allows products from the urban farms to be stolen. But for social capital to be strong it must be supported by other mechanisms, especially in urban environments where there is a complexity of activities. The emergence of neighborhood watches that work hand in hand with law enforcement agencies is one of the developments that has reduced crime rates in some urban residential neighborhoods. But these do not seem to exist in KwaMashu, and the police are not helpful either. It can therefore be concluded that in the context of KwaMashu, urban agriculture is a peripheral activity that does not have any official recognition or representation and therefore suffers from lack of protection from law enforcement authorities. These views were echoed by one of the respondents, who remarked that,

We do not have people who represent us to the local authority. If we had people who represented us, we would not be suffering from issues like lack of land, lack of security, and inadequate technology. The municipality would recognize us and support us because it would have realized that there are a number of people who are practicing urban agriculture. But as it is now, the municipality does not even know how many people are involved in urban farming.

These views are shared by municipal officials interviewed as key informants, who argue that farmers should organize themselves and have representatives. They further argued that without self-initiative and organization on the part of the farmers, it was difficult for the municipality to attend to individual problems. Such negative responses have been noted by other researchers and it appears to be a common trait in most cities of South Africa (Burger, Geldenhuys, Cloete, Thornton, \& Marais, 2009; Shackleton, Pasquini, Ambrose-Oji, \& Drescher, 2009).

\section{Human Capital and Urban Agriculture}

It was noted in the the Livelihood Approach section that human capital is associated with labor, 
health, education, and other related skills. In the case of KwaMashu, human capital can be analyzed from two main perspectives: the educational levels of the urban farmers and the labor-intensive nature of urban agriculture. In the characteristics of urban farmers section above, it was further observed that urban agriculture in KwaMashu is practiced predominantly by people who have a primary education (70 percent), and who to a large extent do not have secure employment. This further contributes to the argument that urban agriculture is a survival activity among the urban poor, since most of them do not have stable sources of income (or if they do, it is not sufficient to meet their needs). In contrast, only 13 percent of those with tertiary education practice urban agriculture, and of those, the type of agriculture some of them practice further indicates that it is not an activity done out of desperation. For instance, some of them raise poultry while others raise goats for sale, and they may even have employees to assist them. However, of all the urban farmers interviewed, none was trained in basic agricultural practices other than learning through trial and error.

\section{Plate 3. Urban Farmers Building a Chicken Run in KwaMashu}

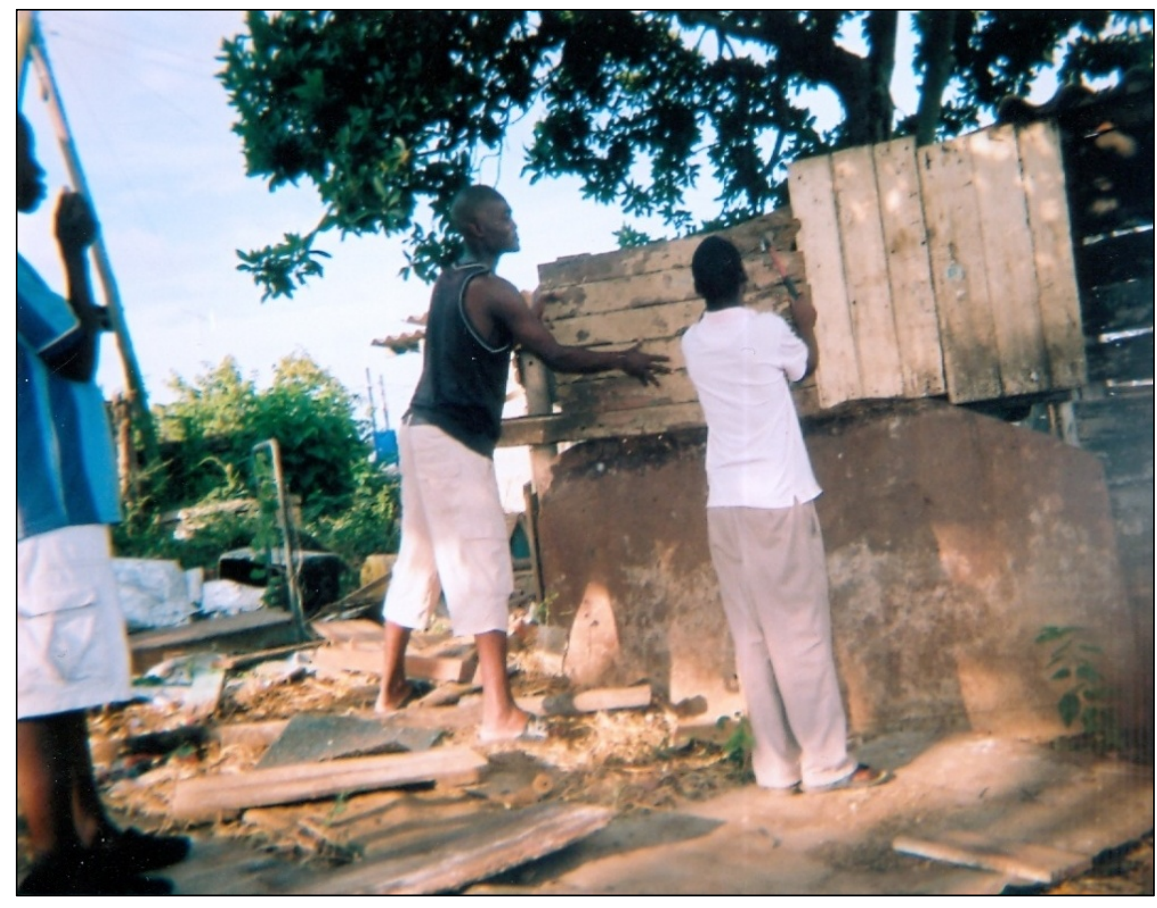

Photo by H. H. Magidimisha, 2009.
Another observation about urban agriculture in KwaMashu is that it is labor-intensive, and is largely dependent on family members, with women being the most active participants. This is a common trend that has been observed in other cities (Burger et al., 2009). It is only in a few situations (such as farmers rearing goats) that employees beyond family members are found. But this is expected given the scale and purpose of production, where 80 percent of the products are meant for household consumption and only 15 percent being sold on the market. This observation, however, contradicts some respondents' (50 percent) argument that lack of technology retards production. It is not clear what type and level of technology is required given the ad hoc nature of the urban farming activities. This aspect of human capital further strengthens the argument that urban agriculture in KwaMashu is basically a survival activity among poor households.

\section{Financial Capital and Urban Agriculture}

An economic overview of KwaMashu and of urban farmers shows that close to 80 percent of households are living below the poverty line due to the lack of or nature of employment combined with their low income levels. This to a large extent reveals the high level of vulnerability among the urban residents. It further ushers in the importance of, yet also the inadequacy of, access to financial capital among urban farmers. This aspect has far-reaching effects on urban farmers since it also contributes to their inability to make urban agriculture more effective. For instance, among farmers who do community gardening and raise livestock, it is one of the factors that contribute to their inability to acquire proper equipment and 
materials, as can be seen in plate 3 where recycled materials are used for a chicken run. In addition, the issue of security for farmers using community gardens and off-site lots could be solved through the use of financial capital for either buying fencing or employing security guards.

Lack of financial capital makes the whole venture unsustainable, further marginalizing urban farmers.

\section{Recommendations}

The preceding sections have presented and discussed the major issues that are associated with urban agriculture in South Africa as represented by the case study of KwaMashu. A number of issues have been identified in this paper, both positive and negative, that affect the practice of urban agriculture as well as the survival of the urban poor. Urban agriculture is practiced through individual initiative without much support from the local government. If urban agriculture is to make a profound contribution to the survival of the urban poor, there is a need to address the various challenges associated with its practice as outlined in the previous section.

The greatest challenge to urban agriculture as a survival strategy emanates from access to land to practice farming by the urban poor. This is the most important element of natural capital and could have a profound impact on urban agriculture as a tool for survival. Land as natural capital is locked up in the system of urban land use, which does not recognize the value of urban agriculture and therefore denies an opportunity to the urban poor to diversify their coping strategies. If urban agriculture is to contribute significantly to the survival strategies of the urban poor, measures must be put in place to make land available for its practice, especially in light of the majority of urban farmers being tenants rather than owners. There is need to identify plots of land for farming that can be apportioned either to individual households or to groups of farmers. This recommendation goes beyond the capacity of urban farmers alone because it calls for the local authorities to recognize the importance of urban agriculture and incorporate it into the urban land use system.
Access to land should not be seen as the end in itself for solving the problem of urban agriculture; instead it is the first step in providing a broad platform to engage and allow for the use of other forms of capital for the survival of the urban poor. For instance, availability and therefore access to land can be used to reorganize human and social capital through the creation of agricultural cooperatives (in the form of community gardens), which then can be used as a conduit for financial capital. Where cooperatives are registered, members can approach financial institutions for financial support to invest into their activities. Membership in cooperatives can cushion some households from certain shocks they experience in their individual capacity, thereby strengthening their coping strategies and reducing their vulnerability. Recognizing cooperatives could significantly contribute to removing the label of an informal activity from urban agriculture, which in essence makes its operations illegal (Burger et al., 2009).

Another aspect that can improve the coping strategies of the urban poor through urban agriculture is access to physical capital, especially water and electricity. This would allow for increased diversity and production in agricultural practice. This infrastructure can be provided easily when land is officially allocated, thereby making it available in planned areas as opposed to the scattered and undesignated plots currently in use. In reality what defines housing as physical capital beyond shelter is the wider neighborhood and its associated infrastructure, which can allow for social and economic activities that diversify livelihoods.

Because of these considerations, there is a need to take an integrated approach to urban agriculture. This should involve making it part and parcel of the urban system so that it can have a meaningful impact. As long as urban agriculture is seen as a peripheral activity without any infrastructure in place, it will always be sidelined at the expense of other land uses, such as residential, industrial and commercial activities.

There are many avenues for further research on urban agriculture in South Africa. The results presented here indicate that there are other livelihood strategies that households pursue; it would be valuable to know how these strategies compete 
with urban agriculture. Equally important would be to conduct further research into methods for promoting and marketing urban agriculture products beyond household consumption. This could help inform the strategies outlined in the recommendations above, and also help to diversify income for households. This would in turn require research beyond KwaMashu in order to establish a holistic picture about Durban and South Africa at large. As a top priority, limitations on urban agriculture emanating from the municipality should be investigated with the aim of establishing future plans.

\section{Conclusion}

In view of the topical nature of urban agriculture in contemporary urban discourse, it would be easy to conclude that urban agriculture is here to stay and the onus is on urban managers to accommodate it. This is a challenge urban planners will have to contend with given the continual informalization of global south cities and the unprecedented increases in urban population. These developments are putting pressure on the urban environment, and especially on the provision of urban services for vulnerable urban households. Under these circumstances, urban agriculture is emerging as a survival strategy such households can rely on to endure the unprecedented and harsh realities of the urban environment. For many, urban agriculture has become a major sources of income and food. This is expected given the meager employment incomes such groups are earning. Ventures into urban agriculture, however, have remained peripheral due to the hostile reception experienced from local authorities. As the research findings have shown, there is still a lack of appreciation among urban managers that urban agriculture can be accommodated in the urban landscape. Driven by modernist principles of planning, these urban managers still view urban agriculture as an activity not compatible with the urban environment. Thus it does not receive adequate attention in the planning system, and this in turn has resulted in unsustainable practices at the expense of both households and the city environment. As long as urban agriculture is not recognized and supported by urban managers, the practice will remain peripheral and unsustainable - which aggravates the already deplorable situation of the urban poor.

\section{References}

Altman, M., Hart, T. GB., \& Jacobs, P. T. (2009). Household food security status in South Africa. Agrekon, 48(4), 345-361. http://dx.doi.org/10.1080/03031853.2009.9523831

Austin, A., \& Visser, A. (2002). Study report: Urban agriculture in South Africa (Report No. BOU/1243). Pretoria: Council for Scientific and Industrial Research (CSIR).

Ayaga, G., Kibata, G., Lee-Smith, D., Njenga, M., \& Rege, R. (2005). Policy prospects for urban and peri-urban agriculture in Kenya. Lima, Peru: Urban HarvestInternational Potato Center. Retrieved from International Potato Center website: http://cipotato.org

Burger, P., Geldenhuys, J. P., Cloete, J., Marais, L., \& Thornton, A. (2009). Assessing the role of urban agriculture in addressing poverty in South Africa (Working Paper No. 28). New Delhi: Global Development Network. Retrieved from http://gdnet.org

Carney, D. (2005). Sustainable livelihoods approaches: Progress and possibilities for change. London: Department for International Development. Retrieved from the Eldis website: http://www.eldis.org/vfile/upload/ 1/document/0812/SLA_Progress.pdf

Chambers, R., \& Conway, G. R. (1992). Sustainable rural livelihoods: Practical concepts for the $21^{\text {st }}$ century (Discussion Paper 296). Brighton, UK: Institute of Development Studies. Retrieved from http://www.ids.ac.uk

Coovadia, Y. Y. (1995). Urban agriculture as a survival strategy: Implications for planning. Durban, South Africa: University of Natal.

Derek Davids, Y. (2006). Impact of perceptions of poverty on the well-being of South Africans. Cape Town: Human Science Research Council [HSRC]. Retrieved from http://www.hsrc.ac.za

Kekana, S. D. (2006). A socio-economic analysis of urban agriculture: The Soshanguve Project (Unpublished doctoral dissertation). University of Pretoria, South Africa.

Krantz, L. (2001). The sustainable livelihood approach to poverty reduction: An introduction. Stockholm: Swedish International Development Cooperation Agency, Division for Policy and Socio-Economic Analysis. 
Mbiba, B. (1995). Urban agriculture in Zimbabwe: Implications for urban management and poverty. Aldershot, UK: Avebury.

McCallum, D., \& Benjamin, S. (1985). Low-income urban housing in the Third World: Broadening the economic perspective. Urban Studies, 22(4), 277287.

Mubvami, T., \& Mushamba, S. (2006). Integration of agriculture in urban land use planning and adaptation of city regulations. In R. van Veenhuizen (Ed.), Cities farming for the future: Urban agriculture for green and productive cities (pp. 53-74). Leusden, the Netherlands: RUAF Foundation, International Development Research Centre (IDRC), and International Institute of Rural Reconstruction (IIRR). Retrieved from IDRC website: http://www.idrc.ca/

National Environmental Management Act, No. 46. (2003).

Njokwe, B. J., \& Mudhara, M. (2008). Urban agriculture in Msunduzi Municipality, South Africa. Urban Agriculture Magazine, 19, 39-43.

O'Laughlin, B. (2004). Book reviews. Development and Change, 35(2), 385-403. http://dx.doi.org/10.1111/ j.1467-7660.2004.00357.x

Onyango, C. L. (2010). Urban and peri-urban agriculture as a poverty alleviation strategy among low income households: The case of Orange Farm, South Johannesburg (Master's thesis). University of South Africa, Johannesburg. Retrieved from http://uir.unisa.ac.za/xmlui/handle/10500/3562

Parkinson, S., \& Ramírez, R. (2006). Using a sustainable livelihoods approach to assessing the impact of ICTs in development. Journal of Community Informatics, 2(3). Retrieved from http://ci-journal.net/

Rakodi, C., \& Lloyd-Jones, T. (2002). Urban livelihoods: A people-centred approach to reducing poverty. London and Sterling, Virginia: Earthscan.

Reddy, T. \& Sokomani, A. (2008). Corruption and social grants in South Africa (Monograph 154). Cape Town,
South Africa: Institute for Security Studies.

Retrieved from http://www.issafrica.org/

Republic of South Africa (2007). Millennium Development

Goals: Goal 1: Eradicate extreme poverty and hunger.

Pretoria, South Africa.

Robinson, P. S., Brown, A. L., Todes, A. E., \& Kitchin, F. (2003). Methods of achieving integration in development planning: Early experience from South African municipalities. International Development Planning Review, 25(3), 263-281. http://dx.doi.org/10.3828/idpr.25.3.3

Rogerson, C. M. (1997). Globalisation or informalisation? African urban economies in the 1990s. In C. Rakodi (Ed.), The urban challenges in Africa: Growth and management of its large cities [HTML version]. Retrieved from http://archive.unu.edu/

Shackleton, C. M., Pasquini, M. W., Ambrose-Oji, B., \& Drescher, A. W. (2009). Promoting indigenous vegetables in urban agriculture and livelihoods: Policy lessons from subSaharan Africa (Policy brief No. 6). Retrieved from Rhodes University, Department of Environmental Science website: http://www.ru.ac.za/static/ departments/environsci/

South Africa Department of Environmental Affairs and Tourism (2000). White paper on sustainable coastal development in South Africa. Retrieved from Polity website: http://www.polity.org.za/polity/govdocs/ white_papers/coastal/

Statistics South Africa. (2007). Community Survey.

Pretoria, South Africa. Retrieved from

http://www.statssa.gov.za/community new/ content.asp

Toner, A. (2002). Sustainable livelihood approaches: Can they transform development? (BCID Research Paper No. 2). Bradford, UK: Bradford Centre for International Development (BCID), University of Bradford.

Vorster, J. (2006). Study on incentive structures of social assistance grants in South Africa: Quantitative report. Cape Town, South Africa: University of Stellenbosch. 